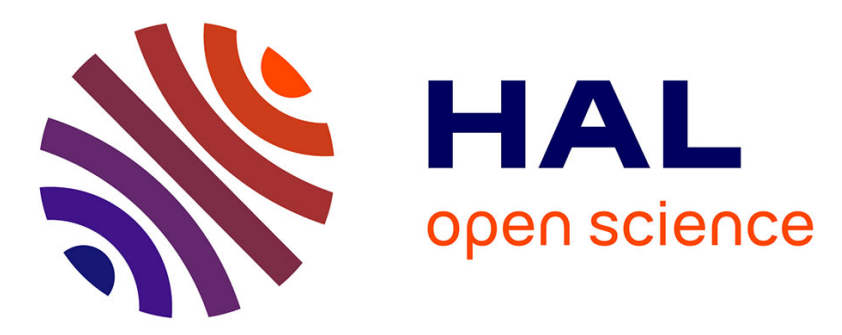

\title{
Surface Spin-Wave in Monocrystalline, Epitaxial Layers of Manganese Ferrite
}

\author{
J. Baszynski
}

\section{To cite this version:}

J. Baszynski. Surface Spin-Wave in Monocrystalline, Epitaxial Layers of Manganese Ferrite. Journal de Physique IV Proceedings, 1997, 07 (C1), pp.C1-447-C1-448. 10.1051/jp4:19971181 . jpa-00254830

\section{HAL Id: jpa-00254830 https://hal.science/jpa-00254830}

Submitted on 1 Jan 1997

HAL is a multi-disciplinary open access archive for the deposit and dissemination of scientific research documents, whether they are published or not. The documents may come from teaching and research institutions in France or abroad, or from public or private research centers.
L'archive ouverte pluridisciplinaire HAL, est destinée au dépôt et à la diffusion de documents scientifiques de niveau recherche, publiés ou non, émanant des établissements d'enseignement et de recherche français ou étrangers, des laboratoires publics ou privés. 


\title{
Surface Spin-Wave in Monocrystalline, Epitaxial Layers of Manganese Ferrite
}

\author{
J. Baszynski \\ Institute of Molecular Physics, 60-179 Poznan, Smoluchowskiego 17, Poland
}

\begin{abstract}
We observed two surface spin-wave modes in ferromagnetic resonance in monocrystalline, epitaxial layers of manganese ferrite (MEFL). The layers, 2 - $3 \mu \mathrm{m}$ thick, were obtained by CVD on monocrystalline MgO substrates. In MEFL, observations were performed at room temperature and a frequency of $26.6 \mathrm{GHz}$. The critical angles for which the surface modes vanish amount to $48^{\circ}$ and $37^{\circ}$, respectively, for line $I$ and II. The magnetic parameters for uniform mode are: $4 \pi \mathrm{M}_{\mathrm{eff}}=$ $280 \mathrm{Gs}, \mathrm{H}_{\mathrm{A}}=-290 \mathrm{Oe}$, and $\mathrm{g}=2.00$.
\end{abstract}

\section{INTRODUCTION}

In recent years, ferrite layers are of particular interest for high frequency and thin-layer inductor applications because of its low conductivity and thus low eddy current losses as compared to metal alloy film [1]. The study of surface modes in spinwave resonance (SWR) are a source of highly relevant information concerning the surface properties of magnetic materials and their bearing on the magnetic properties of bodies, especially in the form of thin layers. Yu et al. [2] by introducing a phenomenological parameter of surface anisotropy in Puszkarski theory [3,4], succeeded in achieving a compact description of the experimental results for garnet layers. With regard to ferrites layers having the spinel structures and high $\mathrm{M}_{\mathrm{S}}$ and $\mathrm{T}_{\mathrm{C}}$ as compared to garnet layers, such studies are still in their initial stage [5].

\section{EXPERIMENTAL RESULTS}

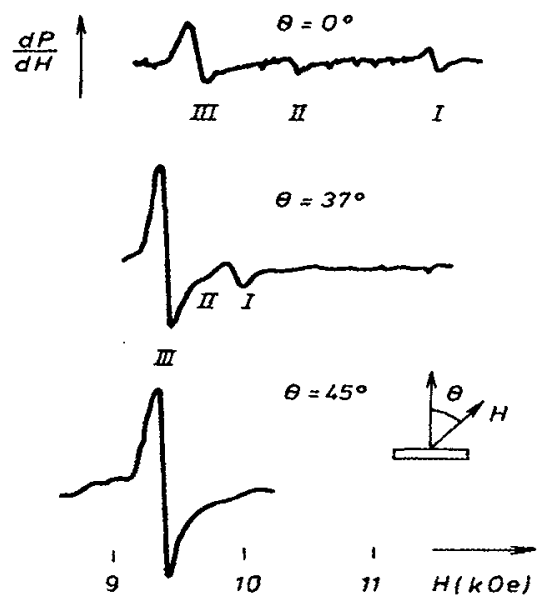

Figure 1: FMR spectrum versus the angle $\Theta$ between MEFL normal and extemal magnetic field $\mathrm{H}$, at $26.6 \mathrm{GHz}$ and room temperature.

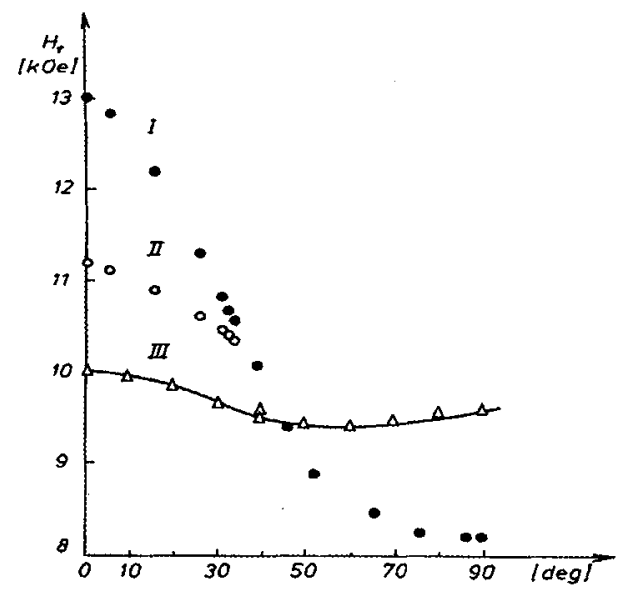

Figure 2: Resonance field strengths $H_{r}$ versus $\Theta$ for the lines of the FMR spectrum. 
The specimens used in this work were monocrystalline, epitaxial layers of Mn-ferrite, $2-3 \mu \mathrm{m}$ thick, obtained by CVD on monocrystalline $\mathrm{MgO}$ substrates [6] at $1500^{\circ} \mathrm{K}$. Their surfaces were crystallographical ( 100 ) planes.

The microwave spectrometer used in our experiments was of the standard reflection type operating at $26.6 \mathrm{GHz}$ frequency range. The SWR spectrum was detected as the first derivative of the absorption signal using a $1 \mathrm{KHz}$ modulation field. The applied magnetic field was directed along the $(010)$ direction in the surface of the ( 100$)$-oriented layer. The FMR were observed versus the angle $\Theta$ between the magnetic field direction and the normal to the layer, at room temperature.

Fig. 1 shows our FMR spectra with surface modes as well as their variations in position and intensity versus the angle $\Theta$ between the MEFL normal and external magnetic field.

Fig. 2 shows the angular dependence of the resonance field for the two high-field modes i.e. the surface modes, as well as for uniform mode.

By chemical etching of the surface layer, we found mode I to be localized at the free surface and mode II at the MEFLsubstrate boundry.

\section{DISCUSSION}

The FMR spectra shown in Fig. 1 consist of three lines. The low-field line is a "superposition" of bulk SWR lines, whereas the high-field lines are related with the surface modes. This situation exists in thick layers ( thickness $2-3 \mu \mathrm{m}$ in our case ), and in bulky magnetics [7].

The shape of the spin-wave resonance spectrum depends on the boundary conditions, and can be described in terms of the surface parameter $A_{S}$ introducing a tensorial form of the surface anisotropy for conical symmetry in Puszkarski's model [2]

$\mathrm{A}_{\mathrm{S}}=1-\left[\mathrm{g} \mu_{\mathrm{B}} / 2 \mathrm{SZJ}\right]\left[\mathrm{K}_{\perp} \cos ^{2} \Phi+\mathrm{K}_{/ /} \sin ^{2} \Phi\right]$

with: $\mu_{B}$ - Bohr's magneton, $S$ - atomic spin, $Z$ - number of nearest neigbours, $J$ - exchange integral. The functional dependence of anisotropy energy on $\Phi$, the angle between magnetic field and normal to the layer, is the same as in (1). $K_{\perp}$ is the component of the anisotropy field tensor when the magnetization is normal to the film surface, the $K_{/ 1}$ is the in-plane component of the anisotropy field tensor.

Applying the criterion of surface parameter value, the FMR spectra obtained are of three kinds:

1/ $A_{S}<1$ - only bulk resonance lines are present,

2/ $A_{S}=1$ - the spectrum reduces to a single resonance line ( uniform mode),

3/ $\mathrm{A}_{\mathrm{S}}>1$ - the first resonance line of the spectrum is of surface mode nature.

By varying the angle between the magnetization direction and the plane of the sample by means of an external magnetic field, one modifies the value of $A_{S}$.

The condition for critical angles $\Theta_{\mathrm{cr}}$ when the FMR spectrum reduces to a single resonance line is given by eq. 2 ,

$\operatorname{tg} \Theta_{\mathrm{cr}}=\left(-\mathrm{K}_{\perp} / \mathrm{K}_{/ /}\right)^{1 / 2}$

The critical angles, defined by eq. 2 , were determined from the graphs of Fig. 2 leading to $\Theta_{\mathrm{cr}}=48^{\circ}$ for mode $\mathrm{I}$ and $\Theta_{\mathrm{cr}}=37^{\circ}$ for mode II.

The angular dependence of $H_{r}$ for mode III shown in Fig. 2 is described by the following parameters: $4 \pi \mathrm{M}_{\mathrm{eff}}=280 \mathrm{Gs}$, $\mathrm{H}_{\mathrm{A}}=-290 \mathrm{Oe}$, and $\mathrm{g}=2.00$.

The presence of resonance lines for the surface modes in MEFL is due to magnetic inhomogeneity of the boundary layer at the substrate as well as of the free surface. A detailed and comprehensive of the surface magnetic properties of MEFL as well as the intrinsic mechanism will be published in a forthcoming paper.

\section{CONCLUSIONS}

We studied here by FMR method a surface magnetic properties of monocrystalline, epitaxial layers of manganese ferrite grown on MgO. Surface modes in FMR provide a convenient method for the study of these properties, which play an essential role in an exchange-coupled system.

\section{References}

[1] Suzuki Y., van Dover R.B., Gyorgy E.M., Phillips J.M., and Felder R.J., Phys.Rev., B53 (1996) 14016-14019 and references therein.

[2] Yu J.T., Turk R.A., and Wigen P.E., Phys.Rev,,B11 (1975) 420 - 434

[3] Puszkarski H., Acta Phys.Polon., A38 (1970) 217-238; 899 - 914.

[4] Puszkarski H., Phys.Stat.Sol., 38 (1970) K145-K148.

[5] Parshin A.S., Tchistiakov N.S., Fiz.Tverd.Tela, 18 (1976) 58 - 61.

[6] Baszyński J., „Monocrystalline, epitaxial growth of ferrite layers from the vapour by chemical transport”, 2nd Conference on Advances in Magnetic Materials and their Applications, IEE Coference Publication Nr. 142, London 1976, pp. 1-4.

[7] Murtinova L. and Frait Z., Phys.Lett.A, 40 (1972) 29 - 30. 